\title{
Nice insulins, pity about the evidence
}

\author{
F. Holleman • E. A. M. Gale
}

Published online: 19 July 2007

(C) Springer-Verlag 2007

In February 2006 the German Institute for Quality and Efficiency in Healthcare (IQWiG), an independent body with a mandate to assess the evidence for medical interventions, released its final report on the use of short-acting insulin analogues in the treatment of type 2 diabetes. The report found no advantage over soluble (regular) human insulin. Given that analogues cost more than soluble insulin, the report concluded that there was no evidence to support their use in patients with type 2 diabetes [1]. A subsequent report concluded that the benefits of shortacting analogues in type 1 diabetes were marginal at best [2], and a report on the long-acting analogues is on its way: many suspect that this will be almost equally negative.

Although some have taken issue with the way in which the analysis was performed, for reasons to be discussed later, the conclusions of the initial report were not unexpected. It was not so much the advice that provoked controversy as the fact that it was acted upon: healthcare purchasers decided that they would no longer reimburse the costs of short-acting analogues prescribed for patients with type 2 diabetes. The response from some industry representatives, patient bodies and clinicians was one of predictable outrage. From the point of view of industry, the German pharmaceutical market is worth 37.8 billion euros per year [3], third only in importance to those of the

\section{F. Holleman}

Department of Internal Medicine, Academic Medical Center,

University of Amsterdam,

Amsterdam, the Netherlands

E. A. M. Gale $(\bowtie)$

Diabetes and Metabolism, Medical School Unit,

Southmead Hospital,

Bristol BS10 5NB, UK

e-mail: Edwin.Gale@bristol.ac.uk
USA and Japan, and analogues have a larger share of insulin sales in Germany than anywhere else in the world. Patients were affected at a more personal level, for many link their safety and well-being to an insulin formulation that suits them, and feel threatened if someone proposes to take this away. Some physicians were equally displeased, for clinicians notoriously dislike challenges to their autonomy and judgement. Add to this volatile mix the fact that some (but by no means all) patient organisations and clinicians are well-funded by industry, and you have a recipe for trouble.

Most of the anger was directed towards IQWiG, and the debate that followed was loud and sometimes ugly. Peter Sawicki, Chairman of IQWiG, had his name dragged through the media. A petition to the government protesting at the withdrawal of the analogues was signed by 180,000 patients, and 'independent' commentators duly appeared in the media to discredit the report [4]. The outcome was revealing. The insulin manufacturers denied the evidence, but they did not dispute it. Instead, they simply opted to reduce the price of their quick-acting analogues to match that of human insulin, and the concerns of the healthcare providers melted away. Story over? Not quite.

\section{A brief history of insulin}

The first insulin preparations were painfully produced yet of limited quality. The 'thick brown muck' that Banting injected into Leonard Thompson on 11 January 1922 had no discernible clinical benefit, and the bench skills of Collip were needed to produce the extract that saved Thompson's life [5]. It then took the expertise and resources of Eli Lilly to translate this into a fully effective therapy that could be offered to thousands of people. 
Crystallisation of insulin by Abel in 1926 resulted in improved purity, but meant that insulin was more quickly absorbed, and therefore more rapidly washed out of the system. Somogyi demonstrated that stable control could be achieved with four daily injections: one before each meal, and one at 03:00 hours [6]. A long-acting insulin was clearly needed, and many additives were tried before Hagedorn stumbled upon the idea of adding an alkaline protein to render insulin less soluble at a neutral $\mathrm{pH}$ [7]. Protamine, until recently derived from fish sperm, proved an excellent retarding agent, but it took Nordisk chemists another 10 years to obtain a stable neutral solution by mixing soluble insulin with protamine in isophane (precisely balanced) proportions. This became known as NPH (neutral protamine Hagedorn) or isophane insulin [8]. (For a brief overview of the key figures in history of insulin, see Fig. 1.)

Chemists at Novo, meanwhile, established that addition of zinc to a neutral insulin solution created crystals of varying size that dissolved very slowly after injection. These became the zinc or lente insulins, and much effort went into finding the best mix of small and large crystals to make a 'once-daily' insulin. Use of large crystals alone produced ultralente, the first long-acting insulin to claim a 'peakless' action. And there it rested. Despite endless attempts, no better means of retarding the action of insulin other than protamine or zinc could be found until genetically modified insulins became available 50 years later.
It seems a fundamental rule of medical progress that every solution creates fresh problems. Insulin treatment was always, as Maurice Chevalier said of old age, to be preferred to the alternative, but early preparations frequently caused unpleasant allergic reactions at the injection site, which sometimes swelled to angry lumps half the size of an orange. The long-acting insulins made it possible for diabetes to be treated with one or two daily injections, but at the cost of unpredictable control and bouts of prolonged hypoglycaemia. Some patients entered a twilight world in which they experienced hours of subnormal glucose levels; others might unexpectedly collapse into coma, drive their car off the road, fall into a fighting frenzy or have a convulsion in their sleep.

\section{The insulin wars begin}

Time passed, and little changed. Most manufacturers were satisfied to cater for their own national requirements, and physicians regarded insulin as a generic product, much as we think of petrol. The impetus for change came from Denmark, a small country forced to look to a wider world by its size and the bitter sibling rivalry between its two manufacturers, Nordisk and Novo. The next phase of the story began in 1941, with a Swedish physician called Jorpes. It happened that a patient came to see him one day with very distressing allergic problems due to insulin. By
Fig. 1 Insulin milestones
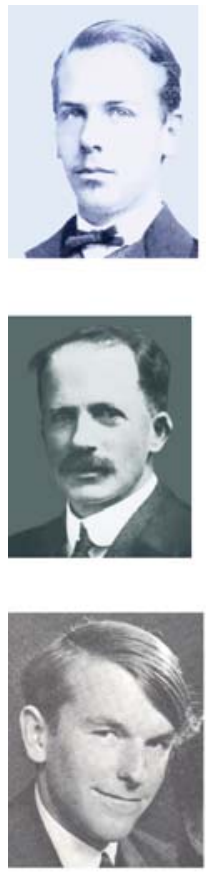

Paul Langerhans

Apologised to his examiners for the lack of novelty in the thesis which contained the first description of pancreatic islets. The islets were named for Langerhans in 1893 by a Frenchman called Laguesse, in a paper in which he speculated that this group of cells was responsible for an internal secretion of the pancreas.

Oskar Minkowski Established the pancreatic origin of diabetes, and went on to show that a blood-borne secretion was responsible for preventing hyperglycaemia.

John James Rickard Macleod

A modest man who played an important role in the discovery of insulin but was glad to 'shake the dust of Toronto from his shoes'.

Hans-Christian Hagedorn One of the great insulin pioneers, whose NPH formulation continues to benefit millions of people.

\section{Frederick Sanger}

Another modest man, who worked almost alone for years to determine the primary sequence of insulin, an achievement which led to his first Nobel Prize.
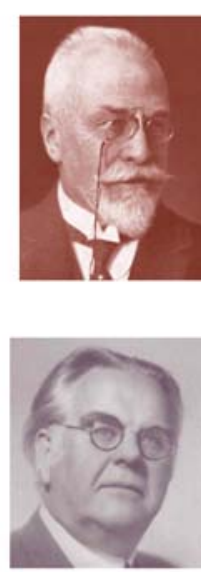

Dorothy Hodgkin Won her Nobel Prize for the structure of vitamin $B_{12}$ before going on to determine the three-dimensional configuration of insulin. 
chance he had some highly purified insulin sitting on his desk: he had prepared this for a laboratory experiment by means of repeated crystallisation. On impulse he treated the patient with it, and solved her problems. Of an estimated 15,000 patients on insulin in Sweden, some 300 had insulin allergy, and all responded to insulin prepared by multiple recrystallisation [9]. This showed that insulin allergy was due to residual impurities in the preparation, and the quest for improved purity was launched. Steiner later used gel electrophoresis to demonstrate two peaks adjacent to that of insulin itself, one due to contaminants and the other to proinsulin. Additional steps in manufacture eliminated these peaks, and the result was a new generation of 'clean' insulins [10].

The new monocomponent (Novo), highly purified (Nordisk) or single peak (Lilly) pork insulins put an end to the disfiguring lipodystrophies that only senior physicians can now remember, but did little in themselves to improve glucose control. Not that this mattered, however, for the new insulins coincided with the era of intensified therapy that followed the landmark year of 1976: blood glucose monitoring, $\mathrm{HbA}_{1 \mathrm{c}}$ measurement, basal bolus therapy and insulin pumps had also entered the scene. Glycaemic control began to improve and the new insulins took some of the credit.

On 24 May 1976, Eli Lilly invited a number of leading molecular biologists to Indianapolis (IN, USA) to talk about insulin. Lilly then held about $85 \%$ of the US market, and was well able to respond to the challenge of the cleaner insulins emerging from Denmark. The steady rise in the incidence of diabetes was more of a concern, for 1.5 million Americans were already taking insulin, with a year-on-year increment of about 5\%. Extrapolation suggested that at some future date there would be more people with diabetes than pancreases. The scientists, meanwhile, had scented that the time was fast approaching when bacteria could be manipulated to make a protein. If so, insulin was the obvious protein to make, and each wanted to be the one to make it. And, if something big was going to happen with insulin, the company wanted to be there [11].

After many adventures, biosynthetic human insulin was on the market by 1983. This magnificent and costly achievement was a remarkable demonstration of what academic science and industry can do by working together. Lilly now had human insulin, and all that remained was to persuade people that they wanted to use it. The problem, well concealed within a blizzard of scientific papers and rhetoric, was that human insulin had no discernible advantage over highly purified pork insulin [12]. No clinical advantage, maybe, but the sales message played well-human insulin is for humans, pig insulin is for pigs. Armed with this message, Lilly launched an invasion of the European heartland. Since only the major players could now afford to compete, the smaller national manufacturers began to fall by the wayside. Aided by a somewhat inept marketing initiative by Lilly, the newly merged NovoNordisk not only survived the challenge, but had its own chemically modified human insulin on the market before Lilly even reached Europe [11]. Its biosynthetic version, engineered in yeast, followed a few years later.

\section{Shaping the market}

Novo-Nordisk now faced the problem that it had to run production lines for both animal and human insulins to supply the European market, whereas Lilly only had human insulin. Clinicians were in no great hurry to change their patients from animal insulins, so the company decided to expedite matters by withdrawing pork insulin. Far from responding to the market, a manufacturer now set a new precedent by telling the market what it was going to get. As a result, and within the space of 6 years, the insulinrequiring population of Europe had been changed to a more expensive insulin that it did not really need.

Instead of welcoming the change, some patients disliked human insulin, which differed slightly in speed of absorption from the pork insulin they were used to. Reports claimed that patients transferred to human insulin lost their warning symptoms of hypoglycaemia, and human insulin was also held to blame when a succession of young people treated with insulin died unexpectedly in their sleep. Public fears were easily aroused by the spectre of genetically modified insulin [13]. In the event, blinded crossover trials revealed that patients who reported loss of warning on human insulin could not tell the insulins apart $[14,15]$. No sensible and humane physician or manufacturer would, however, attempt to deny the validity of patient experience, so Novo-Nordisk had little option but to maintain a supply of animal insulins for those who wanted them.

\section{Superhuman?}

Since insulin could now be manipulated almost at will, humans had the unprecedented opportunity to improve upon their own molecular evolution. Three advantages were hoped for. First, the slow absorption and delayed clearance of soluble insulin caused blood glucose to rise too high after each meal, and to fall too low before the next. Second, intermediate-acting insulins failed to achieve stable background levels of circulating insulin; administered overnight, they peaked too early, predisposing to nocturnal hypoglycaemia, and dissipated too soon, causing a rapid escape of blood glucose before breakfast. Third, insulin absorption 
was notoriously erratic, thus causing unpredictable fluctuations in glucose control. Rapidly absorbed analogues were expected to solve the first problem, and improved longacting insulins to solve the others.

\section{Speeding the absorption of insulin}

The trick was to introduce changes that would reduce the self-aggregating properties of the molecule without affecting its biological actions. AspB10 insulin, developed by Novo-Nordisk, was the clear leader in this race until rat mammary tumours appeared in the course of toxicology studies. Insulin lispro (Lilly) was thus the first analogue to reach the market, followed in due course by insulin aspart (Novo-Nordisk).

The marketing campaign for the quick-acting analogues was largely based around convenience. The argument was that regular insulin should be given up to $40 \mathrm{~min}$ before meals in order to maximise glycaemic control, a point rarely emphasised in the previous literature, whereas quick acting analogues could be given immediately before food. This neatly exploited a logical gap in the thinking of clinicians, for several studies had demonstrated that postprandial glucose control is enhanced by an interval between injections and meals [16], but no study had ever shown that this influenced overall control. The regulatory authorities were persuaded that blinded comparisons were impracticable or even unethical because of this difference in timing, ignoring the reality that the great majority of patients on standard insulin also inject very shortly before eating. A single double-blind trial did however show better postprandial control on the analogue, with better preprandial control on regular insulin; there was less nocturnal hypoglycaemia on the analogue but $\mathrm{HbA}_{1 \mathrm{c}}$ was identical-and the patients were unable to tell the insulins apart [17]. The identical picture has emerged from a mass of non-blinded trials [18]; postprandial glucose values decrease, while preprandial and fasting glucose values increase. As a result, nocturnal hypoglycaemia occurs slightly less frequently, but the overall difference in hypoglycaemia is small, and the difference in $\mathrm{HbA}_{1 \mathrm{c}}$ level almost undetectable.

\section{Insulin mixtures}

Insulin mixtures maintain a firm hold on the market for type 2 diabetes, and the manufacturers were not slow to come up with rapid-acting analogue equivalents. As might be expected, the few clinical studies that were done found improved postprandial control following the injections and a slight reduction in nocturnal hypoglycaemia, but overall control did not differ from conventional insulin mixes [19]. Likewise, analogue mixtures perform as well as the longacting insulin analogues under certain conditions, generally those of suboptimal control [20], but the obvious implication that the human mixtures would do equally well under the same circumstances appears to have been ignored. The main rationale for the analogue mixes is that they enable patients to inject shortly before meals with a clear conscience.

\section{Prolonging the action of insulin}

The observation that preprandial glucose values rise with the short-acting analogues helped to promote the idea of improved basal insulin substitution. The first biosynthetic long-acting preparation to approach the market was proinsulin, a molecule that is native to the body and is cleared much more slowly than insulin. Initial studies looked promising, but an excess of cardiovascular deaths persuaded Lilly not to pursue this option further [21]. Novo-Nordisk explored the principle of an insulin that would remain soluble in the vial yet form crystals at subcutaneous $\mathrm{pH}$, thus retarding its own absorption, and came up with NovoSol Basal [22], only to abandon this because of reduced efficacy attributed to subcutaneous insulin degradation. Hoechst (now Sanofi-Aventis) overcame the practical limitations of this concept, and rode into the global market on the back of insulin glargine.

The main marketing message for glargine was that a peakless once-daily insulin with a duration of action of more than $24 \mathrm{~h}$ was now available [23]. Although there is no such thing as peakless absorption [24], this message has led to current sales of 1.6 billion euros per year with an annual growth of $37 \%$. As with the short-acting analogues, no double-blind studies were performed, on the grounds that NPH and glargine can easily be distinguished, the former being cloudy and the latter clear in appearance. And while the open-label 'treat-to-target' clinical studies on glargine were helpful in establishing the concept that fasting plasma glucose targets should be relentlessly pursued in order to obtain maximal efficacy, the actual benefits of glargine over $\mathrm{NPH}$ insulin in these studies were limited to a $15-20 \%$ reduction in hypoglycaemia, mainly at night. Since the studies also showed that up to $70 \%$ of patients with type 2 diabetes do not experience hypoglycaemia at all, these benefits are limited to a minority.

Novo-Nordisk went on to develop insulin detemir, an analogue with a fatty-acid tail attached to the B chain of the insulin molecule. This results in delayed absorption due to increased self-aggregation of insulin under the skin, and buffered action due to binding to circulating albumin [25]. Coming second to the market, detemir has encountered 
greater problems in creating its own demand. The main clinical benefits it offers are reduced weight gain on starting insulin, of the order of $1-1.5 \mathrm{~kg}$, and less nocturnal hypoglycaemia, equivalent to that seen with glargine [26, 27]. Preclinical studies suggest less variability in effect compared with NPH and glargine, but this does not appear to translate into clinically meaningful differences in stability of fasting plasma glucose.

\section{Misguided enthusiasm?}

Although there is clinical enthusiasm for the insulin analogues, particularly glargine, current guidelines are remarkably reticent. The analogues feature merely as a treatment option in the American Diabetes Association (ADA)/European Association for the Study of Diabetes (EASD) guidelines for the management of type 2 diabetes [28], and in the UK National Institute for Health and Clinical Excellence (NICE) guidelines for the management of type 1 diabetes, although the latter are rather out of date [29]. NICE has also offered guidelines for insulin glargine [30]. These find no evidence for better glucose control, but some evidence for reduction in (nocturnal) hypoglycaemia. Any reader of current guidelines would infer that insulin analogues should be reserved for use in selected patients.

This, of course, is not what has happened. The shortacting insulin analogues and their mixes have already secured more than $40 \%$ of the market formerly taken by regular insulins, and insulin glargine has been a runaway success, strongly endorsed by patients and clinicians despite somewhat borderline evidence of benefit. How does one reconcile this discrepancy between market success and objective evidence? The answer is not that difficult. Individual patients often report great benefits when transferred to a new insulin, but this is not remarkable when the transfer is accompanied by enthusiastic advocacy, enhanced motivation and attention to other aspects of patient management [31]. Should all the credit go to the analogue? And will the benefits persist for more than 6 months? We do not know. There is only one fully objective way of evaluating patient benefit and patient preference, and that is the double-blind clinical trial. It is with some despair that we observe that a few well-performed blinded comparisons would have clarified many of the issues discussed in this Editorial. In their absence, we can assume that such comparisons would, like open trials, show no evidence of improved glucose control, with perhaps some reduction in hypoglycaemia. As to whether patient-important outcomes would be affected, or whether patients could even tell the insulins apart, this we can only conjecture, for we have no objective means of deciding.

\section{Putting the evidence together}

Evidence-based medicine has its limitations. Cochrane reviews employ such rigorous selection procedures that the number of publications considered comes to represent less than $5 \%$ of the total. The remaining studies are excluded for reasons including lack of methodological detail in the published reports. This may in itself introduce bias, for a majority of clinical trials do employ appropriate concealment and blinding procedures, although only a minority report these in full [32]. On the other hand, there are indeed serious flaws in reporting many clinical trials, although those sponsored by for-profit organisations tend to be reported more professionally [33]. A more fundamental problem is that such studies may fail to address the questions of greatest clinical relevance because they were designed to meet regulatory guidelines for the introduction of new therapies - guidelines that represent a compromise between comprehensive evaluation and speedy access to potentially valuable new therapies. Since there is an additional delay before data obtained during the regulatory process are published - and some studies are not published at all —clinicians have limited evidence upon which to operate when new agents are launched [34]. The resulting information gap coincides with the period when marketing is at its most intense and future prescribing habits are established.

How valid are Cochrane or other systematic reviews when it comes to the insulin analogues? Concerns have been expressed. One argument is that clinical trials may have been biased because participating clinicians were more expert at using the older insulins. This is unconvincing, since most study protocols provide strict guidelines, and the 'treat-to-target' trials all but removed personal inexperience from the equation. Another concern relates to interpretation: data for $\mathrm{HbA}_{1 \mathrm{c}}$ levels and hypoglycaemia are analysed and presented separately, whereas their inverse relationship requires combined analysis. This limitation does however arise from the way in which the original studies were reported. Another possibility is that important benefits may have been overlooked in certain subgroups, or may only emerge when insulins are used to full advantage. Finally, combined use of short- and long-acting analogues is likely to maximise their benefits; two open-label studies comparing combinations of short and long-acting analogues with regular and NPH insulins have reported reductions in $\mathrm{HbA}_{1 \mathrm{c}}$ levels of $0.22(95 \% \mathrm{CI}-0.34$ to -0.10$) \%$ and 0.5 (95\% CI -0.7 to -0.3$) \%$ with less nocturnal hypoglycaemia (55\% and $44 \%$ respectively) $[35,36]$.

In summary, evidence-based medicine should function as a guide rather than as a strait jacket. Yes, it has its limitations. Yes, it is not free of the risk of reductionist bias. But, when the alternative is eminence-based medicine, and 
when those who speak favourably of the agents in question are generally well rewarded for doing so, which is to be preferred?

\section{A common sense view of the evidence}

When sensible people disagree, the usual reason is that they are not talking about the same thing. The sceptics base their argument upon studies of less intensively treated patients who receive equal levels of support. Analogue enthusiasts, in contrast, tend to use more intensive regimens, and easily confound the medium with the message - the message being that well-motivated patients with good support do well, regardless of what is in the insulin syringe. Even the most enthusiastic advocate of the insulin analogues would probably agree that there is little or no benefit in switching poorly controlled patients from one insulin to another in the absence of any other intervention, and systematic reviews of the evidence point to the same conclusion.

With regard to the short-acting analogues, it is important to appreciate that basal and overnight glucose levels are the major determinants of $\mathrm{HbA}_{1 \mathrm{c}}$ levels in patients with poor glucose control. Since short-acting analogues affect postprandial glucose, their contribution will only emerge once basal glucose is well regulated. This is why their greatest effect upon $\mathrm{HbA}_{1 \mathrm{c}}$ levels $(0.13 \%)$ is seen in those on insulin infusion pump therapy [18]. Patients with effectively (rather than notionally) intensified glucose control might therefore be expected to derive some minor benefit from short-acting analogues, as might those in difficulties with nocturnal hypoglycaemia. In other circumstances these precision insulins will simply be lost in the ups and downs of everyday glucose control.

Equally, although this is not secure beyond dispute, the evidence for the long-acting analogues indicates that better fasting glucose control can be achieved with less risk of nocturnal hypoglycaemia in those subjected to aggressive dose titration. In the absence of such titration, they offer little or no benefit. There is, in other words, little point in prescribing these insulins in less intensively managed patients, or in those at low risk of nocturnal hypoglycaemia - which effectively excludes the great majority of patients with type 2 diabetes as currently managed, and a substantial proportion of those with type 1 diabetes. Patient preference must be respected, but we should also allow for the power of suggestion. Some clinicians may consider it sufficient that their patients derive benefit, never mind why, but such benefits are impossible to evaluate in the absence of blinded comparisons. The only conclusion to be drawn at present is that prescribing behaviour has been driven by subjective preference rather than objective evidence, and that the studies needed to distinguish between the two have not been performed.

\section{The insulin market}

The production, formulation, purification and bioengineering of insulin over the past 85 years has helped millions of sufferers from diabetes enjoy a better quality of life. Our supply of insulin is secure for the future. Within the limits of protein chemistry, the insulin producers have delivered almost everything that clinicians have asked for in terms of optimised prandial and basal insulin substitution. The road has been long, arduous, and strewn with expensive failures. For all these reasons, the manufacturers deserve our lasting gratitude - not to mention a fair commercial return for their efforts.

As Oscar Wilde said, 'There are only two tragedies in life: one is not getting what one wants, the other is getting it.' We got most of the things we asked for from the insulin analogues, only to realise that this is not enough: for the analogues are only modified delivery systems, and insulin is only insulin. The fundamental limitations of subcutaneous therapy, such as delivery of insulin into the systemic circulation and variable absorption, have not been overcome. Nor, in the short term, are they likely to be. The range of possible molecular permutations of the insulin molecule may be almost infinite, but the number of changes that can be made without altering receptor binding, introducing unwanted biological actions or affecting stability is strictly limited. Are we approaching the limits of subcutaneous insulin therapy?

It is no discredit to the insulin manufacturers to point out that corporations exist to maximise markets and sales. We now have a situation where three manufacturers effectively control an expanding global insulin market worth 8 billion euros. This is known as an oligopoly. Taking all products into account, the income statements for the three companies reported total sales of 45.4 billion euros for 2006 . These sales yielded a net profit of 9.9 billion euros, or $21.8 \%$ (range 16.7-24.8\%). The world paid US\$2 billion for insulin in $1995, \$ 7.3$ billion in 2005 , and is projected to pay $\$ 11.8$ billion in 2010 [37]. How will the members of this oligopoly compete for the insulin market? Not, as we may guess, by cutting the price of insulin. Each will sell its insulins for the best price the market will bear, and, given that the analogues are more profitable on a unit-for-unit basis, each will press hard for extending their use. If the discovery pipeline is indeed running dry, sales can only be increased by intensive marketing. Many fear that the manufacturers, who once forced a change from pork to human insulin, will now endeavour to withdraw human insulin itself. The marketing logic behind such a move is evident, and would be backed by the argument that the analogues are at least no worse, and possibly better, than their human equivalents. Should we resist such a move? And - more to the point — could we? 
The big corporations, pharmaceuticals included, exist in a supranational dimension that limits their accountability to any elected form of government. When possible, they will erect barriers to cheaper products. Where this has been achieved, as in the USA, the consequence has been that $4 \%$ of the world's population pay $50 \%$ of the world's drug bill, only to rank 29th in terms of healthy life expectancy. The pharmaceutical companies are big employers as well as producers, which only adds to their marketing muscle. It is now reflex, for example, for senior executives to respond to any national initiative to cut drug costs by reminding journalists that relocating to a more hospitable environment is among their options. No wonder that even countries with the financial power of Germany might hesitate to take them on.

When market forces rule, the most effective response is via the market. The market for prescription drugs is driven by those who write the prescriptions, and regulated by those who advise them on how to do so. We are all consumers of healthcare: physicians, company employees and patients alike, so it is in everyone's interests to establish the best deal for the consumer. This is why we need evidence-based medicine. Those who dislike its methods or findings should seek to make it better, not to discredit it. Clinicians are conditioned to expect and prescribe the best for their patients, regardless of costs, but there are no blank cheques. How would people in the UK, for example, react when given the choice between treating 150-200 patients with glargine instead of NPH, or employing a full-time diabetes nurse educator at the same cost?

The story of IQWiG is important in this context, not because of the way it interpreted the evidence, which is effectively little different from the conclusions of other consultative bodies, but because its voice resulted in action by the healthcare purchasers. In this instance, the manufacturers blinked first. If Europe as a whole insists upon the need for human insulin, from generic manufacturers if need be, we need not fear that human insulin will be withdrawn. If Europe unites behind the resolution that drug prices should be linked to evidence of benefit, manufacturers would be obliged to provide better evidence or adjust their prices downwards. Otherwise said, if analogues were to cost the same as human insulin, and we could choose freely between them, the controversy concerning their use would soon become irrelevant.

Duality of interest E. A. M Gale prepared the clinical expert reports for Eli Lilly with regard to their submission of Humalog and lispro mixtures for regulatory approval in Europe. He has received lecture fees for speaking at meetings sponsored by Eli Lilly, Novo-Nordisk and Sanofi-Aventis. F. Holleman wrote his $\mathrm{PhD}$ thesis on Eli Lilly's insulin analogue insulin lispro. He is currently principal investigator for a large multinational trial sponsored by Sanofi-Aventis, and has served on advisory boards for Sanofi-Aventis. His stay at the Diabetologia Editorial Office is supported by an unrestricted educational grant from Novo Nordisk.

\section{References}

1. Institut für Qualität and Wirtschaftlichkeit im Gesundheitswesen. Rapid-acting insulin analogues for the treatment of diabetes mellitus type 2: final report. Available from http://www.iqwig.de/download/ A05-04_Final_Report_Rapid-acting_insulin_analogues_for_the treatment_of_diabetes_mellitus_type_2.pdf, accessed 15 June 2007

2. Institut für Qualität and Wirtschaftlichkeit im Gesundheitswesen. Kurzwirksame insulinanaloga zur Behandlung des diabetes mellitus typ 1: vorbericht [Rapid-acting insulin analogues for the treatment of diabetes type 1: preliminary report]. Available from http:// www.iqwig.de/download/A05-02_Vorbericht_Nutzenbewertung kurzwirksamer_Insulinanaloga_zur_Behandlung_des_Diabetes mellitus_Typ_1.pdf, accessed 15 June 2007 [in German]

3. Verband Forschender Arzneimittelhersteller [German Association of Research-Based Pharmaceutical Companies]. Statistics 2006: the pharmaceutical industry in Germany. Available at http://www. vfa.de/download/SHOW/en/vfa en/publikationen en/e statistics/ e_statistics_2006.pdf, accessed 15 June 2007

4. Grill M (2006) Gib dem Affen Zucker [Give the monkey sugar]. Die Stern, 13 June. Available from http://www.stern.de/wissenschaft/ medizin/:Streit-Insulin-Analoga-Der-Selbstbedienungsladen/563128. html?eid=567257, accessed 15 June 2007 [in German]

5. Bliss M (1983) The discovery of insulin. Paul Harris Publishing, Edinburgh

6. Somogyi M (1959) Exacerbation of diabetes by excess insulin action. Am J Med 26:169-191

7. Hagedorn HC, Norman Jensen B, Krarup NB, Wodstrup I (1936) Protamine insulinate. JAMA 106:177-180

8. Deckert T (2000) H. C. Hagedorn and Danish insulin. Poul Christensen Publishing, Herning, Denmark

9. Jorpes JE (1943) Recrystallised insulin for diabetic patients with insulin allergy. Arch Intern Med 83:363-371

10. Brange J (1987) Galenics of insulin. Springer, Berlin

11. Hall SS (1987) Invisible frontiers. The race to synthesize a human gene. Atlantic Monthly, New York

12. Richter B, Neises G (2005) 'Human' insulin versus animal insulin in people with diabetes mellitus. Cochrane Database of Systematic Reviews, Issue 1. Art. No. CD003816. DOI 10.1002/14651858. CD003816.pub2

13. Gale EAM (1989) Hypoglycaemia and human insulin. Lancet ii: $1264-1266$

14. Colagiuri S, Miller JJ, Petocz P (1992) Double-blind crossover comparison of human and porcine insulins in patients reporting lack of hypoglycaemia awareness. Lancet 339(8807):1432-1435

15. Maran A, Lomas J, Archibald H et al (1993) Double blind clinical and laboratory study of hypoglycaemia with human and porcine insulin in diabetic patients reporting hypoglycaemia unawareness after transferring to human insulin. BMJ 306(6879):167-171

16. Lean MEJ, Ng LL, Tennison BR (1985) Interval between insulin injection and eating in relation to blood glucose control in adults. BMJ 290:105-108

17. Gale EAM for the UK Trial Group (2000) A randomized controlled trial comparing insulin lispro with soluble insulin in patients with type 1 diabetes on intensified insulin therapy. Diabet Med 17:209-214

18. Siebenhofer A, Plank J, Berghold A et al (2004) Short acting insulin analogues versus regular human insulin in patients with diabetes mellitus. Cochrane Database of Systematic Reviews. Art. No.: CD003287. DOI 10.1002/14651858.CD003287.pub4 
19. Roach P, Trautmann M, Arora V, Sun B, Anderson JH (1999) Improved postprandial blood glucose control and reduced nocturnal hypoglycemia during treatment with two novel insulin lispro-protamine formulations, insulin lispro mix 25 and insulin lispro mix 50. Clin Ther 21:523-534

20. Raskin P, Hu P, Allen A et al (2005) Initiating insulin therapy in type 2 diabetes: a comparison of biphasic and basal insulin analogs. Diabetes Care 28:260-265

21. Galloway JA, Hooper SA, Spradlin CT et al (1992) Biosynthetic human proinsulin. Review of chemistry, in vitro and in vivo receptor binding, animal and human pharmacology studies, and clinical trial experience. Diabetes Care 15:666-692

22. Jorgensen S, Vaag A, Langkjaer L et al (1989) NovoSol Basal: pharmacokinetics of a novel soluble long-acting insulin analogue. BMJ 299(6696):415-419

23. Lepore M, Pampanelli S, Fanelli C et al (2000) Pharmacokinetics and pharmacodynamics of subcutaneous injection of long-acting human insulin analog glargine, NPH insulin, and ultralente human insulin and continuous subcutaneous infusion of insulin lispro. Diabetes 49:2142-2148

24. De Vries JH (2006) To: Scholtz HE, Pretorius SG, Wessels DH, Becker RHA (2005) Pharmacokinetic and glucodynamic variability: assessment of insulin glargine, NPH insulin and insulin ultralente in healthy volunteers using a euglycaemic clamp technique. Diabetologia 48:1988-1995. Diabetologia 49:1125-1126

25. Havelund S, Plum A, Ribel U et al (2004) The mechanism of protraction of insulin detemir, a long-acting acylated analog of human insulin. Pharm Res 21:1498-1504

26. Hermansen K, Davies M, Derezinski T, Ravn GM, Clauson P, Home P (2006) A 26-week, randomized, parallel, treat-to-target trial comparing insulin detemir with NPH insulin as add-on therapy to oral glucose-lowering drugs in insulin-naive people with type 2 diabetes. Diabetes Care 29:1269-1274 (Erratum in: Diabetes Care [2007] 30:1035)

27. Philis-Tsimikas A, Charpentier G, Clauson P, Ravn GM, Roberts VL, Thorsteinsson B (2006) Comparison of once-daily insulin detemir with NPH insulin added to a regimen of oral antidiabetic drugs in poorly controlled type 2 diabetes. Clin Ther 28:1569-1581
28. Nathan DM, Buse JB, Davidson MB et al (2006) Management of hyperglycaemia in type 2 diabetes: a consensus algorithm for the initiation and adjustment of therapy. A consensus statement from the American Diabetes Association and the European Association for the Study of Diabetes. Diabetologia 49:17111721

29. National Collaborating Centre for Women's and Children's Health (2004) Type 1 diabetes: diagnosis and management of type 1 diabetes in children and young people. RCOG, London, pp 49-56

30. National Institute for Clinical Excellence (2005) Guidance on the use of long-acting insulin analogues for the treatment of diabetes - insulin glargine. Technology Appraisal no. 53. Available at: http://guidance.nice.org.uk/TA53/guidance/pdf/English, accessed 15 June 2007

31. Gale EAM (2004) The Hawthorne Studies: a fable for our times? Q J Med 97:439-449

32. Devereaux P, Choi PTL, El Dika S et al (2004) An observational study found that authors of randomized controlled trials frequently use concealment of randomization and blinding, despite the failure to report these methods. J Clin Epidemiol 57:1232-1236

33. Montori VM, Wang YG, Alonso-Coello P, Bhagra S (2006) Systematic evaluation of the quality of randomized controlled trials in diabetes. Diabetes Care 29:1833-1838

34. Gale EAM (2001) Lessons from the glitazones: a story of drug development. Lancet 357:1870-1875

35. Hermansen K, Fontaine P, Kukolja KK, Peterkova V, Leth G, Gall MA (2004) Insulin analogues (insulin detemir and insulin aspart) versus traditional human insulins (NPH insulin and regular human insulin) in basal-bolus therapy for patients with type 1 diabetes. Diabetologia 47:622-629

36. Ashwell SG, Amiel SA, Bilous RW et al (2006) Improved glycaemic control with insulin glargine plus insulin lispro: a multicentre, randomized, cross-over trial in people with type 1 diabetes. Diabet Med 23:285-292

37. Hauber A, Gale EAM (2006) The market in diabetes. Diabetologia 49:247-252 